\title{
Chromatographic Method for the Fractionation of Asphalt Into Distinctive Groups of Components
}

\author{
Lawrence R. Kleinschmidt
}

\begin{abstract}
A chromatographic method for the separation of asphalt into four distinct groups of components is described. The method utilizes fuller's earth as the adsorbent, and $n$-pentane, methylene chloride, and methyl ethyl ketone as selective solvents. The fractionation of asphalts into components in this manner facilitates the study of the degradation of asphalts in service. Although the method, in general, is not limited by the size of the specimen, it is particularly suited to samples of 3 to 6 grams, in which case it requires from 6 to 8 hours, depending upon the nature of the asphalt, for a complete fractionation. The time required to fractionate the $n$-pentane soluble components is about 3 hours.
\end{abstract}

\section{Introduction}

Asphalts, when exposed to various atmospheric conditions or to accelerated durability tests, undergo changes that have been determined mainly by physical methods. Studies of the chemical changes that occur in blown petroleum asphalts during the weathering process are greatly facilitated by the separation of the asphalts into groups of similar components.

Marcusson [1 $]^{1}$ was one of the first investigators to separate asphalt into three groups of components. $\mathrm{By}$ his procedure, asphalt was digested with $88^{\circ}$ Bé naphtha. ${ }^{2}$ The insoluble portion was designated as "asphaltenes", that adsorbed by certain clays from the soluble portion as "asphaltic resins", and the remainder as "total oily constituents". Strieter [2] improved the method by substituting $n$-pentane for the $88^{\circ}$ Bé naphtha, and effected a nearly complete recovery of all components by using ethyl ether as a desorbent for the asphaltic resins, Hubbard and Stanfield [3] used anhydrous aluminum oxide as the adsorbent for their asphaltic resins. O'Donnell [4] used isopentane for the separation of the asphaltenes, and silica gel as the adsorbent for the asphaltic resins. Various other modifications of these methods are described by Abraham [5]. Grant and Hoiberg [6] and Traxler and Schweyer [7] employed solvents alone in their separations. Rostler and Sternberg [8] used dry hydrogen chloride gas and varying strengths of sulfuric acid for a separation of the $n$-pentane soluble portion of the asphalt.

The conventional specimen of asphalt for both outdoor and accelerated durability tests is usually a $2 \frac{1}{4}$ - by $5^{1 / 4}$-in. film of asphalt on a $2^{3 / 4}$-by 6 -in. aluminum panel. When such a film is prepared in a thickness of about $0.01 \mathrm{~cm}$ (25 mils), approximately $5 \mathrm{~g}$ of asphalt is available for examination. The primary purpose of this investigation was to develop a rapid and reproducible method for fractionating such small samples (3 to $6 \mathrm{~g}$ ) of asphalt into distinct groups of components. This is the preliminary phase of the study of the chemical changes that take place during the degradation of asphalts in service.

1 Figures in brackets indicate the literature references at the end of this paper. ${ }^{2}$ Petroleum mixture of $n$-pentane, isopentane, and cyclopentane $\left(d_{4}^{25}\right.$ about 0.642 ).

\section{Procedure}

A schematic diagram of the method of fractionation is given in figure 1. Specimens of asphalt for fractionation (about $5 \mathrm{~g}$ ) were prepared in the same manner as those used for outdoor and accelerated durability tests, that is, by uniformly leveling the asphalt on a $2 \frac{3}{4}-$ by 6 -in. aluminum panel, using the hydraulic-press method proposed by Greenfeld [9], or by uniformly distributing hot asphalt around the periphery of a 4-in. aluminum disk. The weight of the specimen was readily obtained by weighing the panel or disk before and after applying the asphalt. The large ratio of surface to volume obtained with such specimens facilitated the digestıon with $n$-pentane.

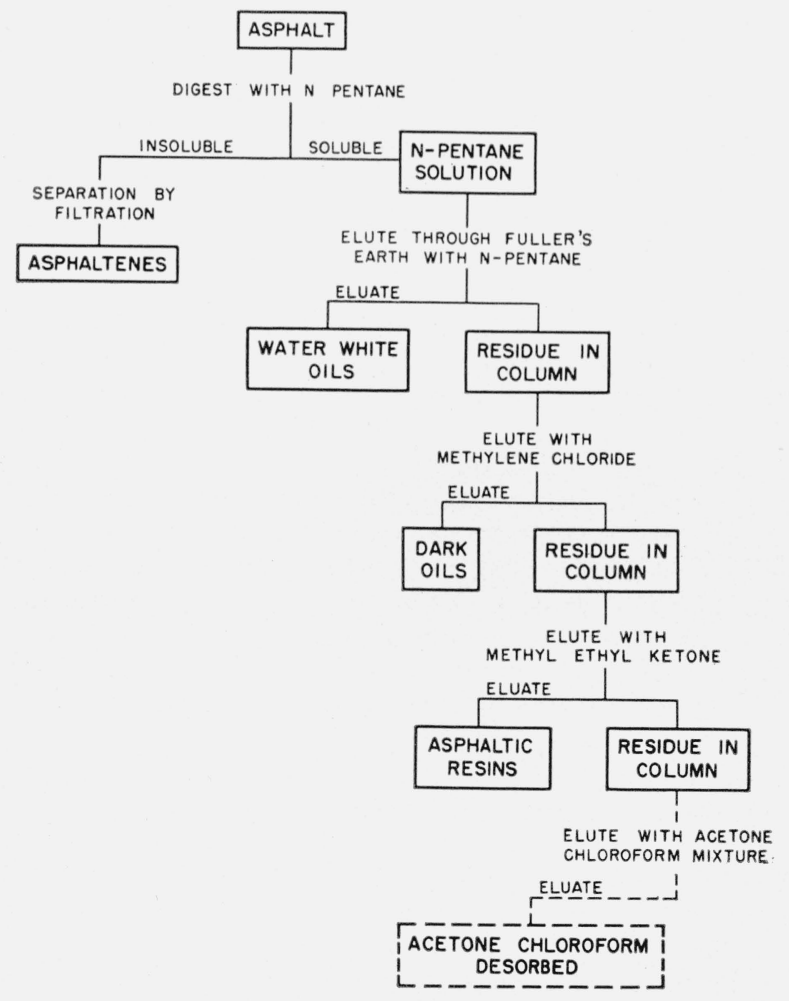

Figure 1. Schematic diagram of method of fractionation. 


\subsection{Separation of the $n$-Pentane Soluble and Insoluble Fractions}

Specimens prepared by either method described above were digested with $n$-pentane $(40 \mathrm{ml}$ for each gram of asphalt) until the undissolved asphalt could be removed readily from the aluminum base with a rubber policeman. The aluminum base was washed free from any adhering material with $n$-pentane and removed from the beaker. The digestion with $n$-pentane was continued for $2 \mathrm{hr}$. The separation of the insoluble material was made by filtering the solution through a porcelain bitumen crucible with an asbestos mat. When the insoluble material was to be used for further study, the asbestos mat was topped with a tightly fitting filter-paper disk. It was found desirable to keep the insoluble matter covered with $n$-pentane throughout the filtration, using a rubber policeman to concentrate the insoluble portion, the bulk of which was readily transferred to the crucible with a spatula. This procedure was desirable because the insoluble portion from some asphalts was quite gelatinous and ahdered tenaciously to the beaker. The $n$-pentane insoluble fraction was washed with $n$-pentane until the filtrate was practically colorless. It was air-dried until free from $n$-pentane, then heated for $30 \mathrm{~min}$ at $105^{\circ} \mathrm{C}$, and weighed. This fraction of the asphalt was designated as asphaltenes.

\subsection{Fractionation of the $n$-Pentane Soluble Components}

The amount of the $n$-pentane soluble portion of the asphalt was taken as the difference between the weight of the original specimen and that of the insoluble asphaltenes. This $n$-pentane soluble portion was fractionated by eluting it through a chromatographic column containing fuller's earth. Three groups of components were obtained from this solution by eluting successively with technical grades of $n$-pentane, methylene chloride, and methyl ethyl ketone. A ratio of 15 to 1 for the weight of the fuller's earth placed in the chromatographic column to that of the $n$-pentane soluble material was found to be convenient. However, the method, in general, is not limited to this ratio, as the procedure in fractionating the $n$-pentane soluble material is the same for any ratio of these two materials.

The chromatographic column (see fig. 2) was prepared by sealing a $3-\mathrm{cm}$ length of $6-\mathrm{mm}$-diameter Pyrex tubing to a $30-\mathrm{cm}$ length of standard-wall Pyrex tubing, approximately $30 \mathrm{~mm}$ in diameter. ${ }^{3}$ A plug of glass wool was tamped into the bottom of the column before adding the fuller's earth ${ }^{4}$ in a continuous stream while tapping the column to compact the adsorbent.

After adding the fuller's earth to the column, a plug of glass-wool was placed over the adsorbent to

3 Columns prepared from 28-, 30-, and 32-mm-diameter tubing will accommodate sufficient fuller's earth for the fractionation of from 1.5- to 3.5-g quantities

of the $n$-pentane soluble material. fuller's earth through a centrifugal air separator. The fuller's earth was heated at $150^{\circ} \mathrm{C}$ for $18 \mathrm{hr}$ prior to use.

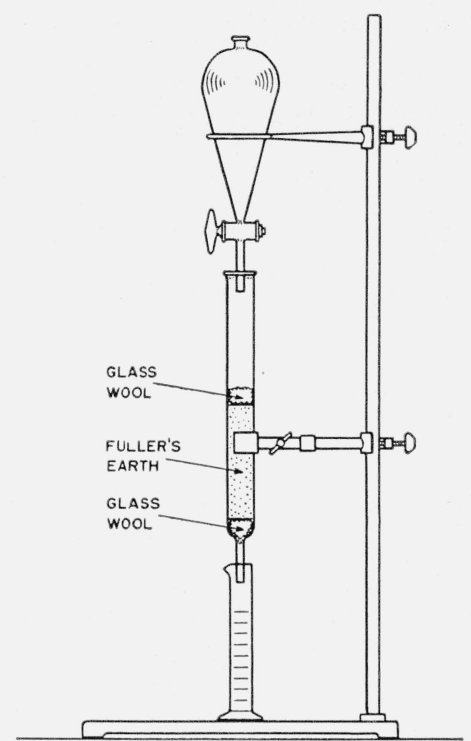

FIGURE 2. Fractionation assembly.

aid in an even distribution of the eluents and to prevent disturbing the column of fuller's earth during the successive elutions. In general, the ratio of the length of the column of fuller's earth to its diameter was approximately 5 to 1 . This permitted a ready flow of all eluents through the column with only the force of gravity. A reservoir consisting of at least one-fourth the volume of the tube was available above the fuller's earth as storage space for the eluents.

The $n$-pentane solution before being fractionated was concentrated to approximately $50 \mathrm{ml}$ by heating on a steam bath. The fuller's earth in the chromatographic column was wetted with $n$-pentane to a depth of approximately 2 in. before adding the $n$-pentane solution. After the solution was placed in the column, $n$-pentane was added in $20-\mathrm{ml}$ portions until the glass-wool plug on top of the fuller's earth was washed free of $n$-pentane soluble components. Sufficient $n$-pentane was then added to the reservoir to maintain a rate of flow of about $5 \mathrm{ml} / \mathrm{min}$ of the eluate. When 2 to $3 \mathrm{~g}$ of $n$-pentane soluble material was to be fractionated, $50 \mathrm{ml}$ portions of the $n$ pentane eluate were collected consecutively, and the amount of nonvolatile material in each was determined.

Rapid evaporation of the $n$-pentane was accomplished without troublesome creepage by placing the beakers, not more than two-thirds full, approximately 15 in. from a $250-\mathrm{w}$ infrared lamp (uncolored glass, reflector type) arranged so that the center line of the rays was parallel to and slightly above the level of the solution. (The red-colored infrared lamp was found to be unsatisfactory for this purpose in that the entire beaker was heated, which resulted in creepage of the nonvolatile constituents.) The sample was then heated at $105^{\circ} \mathrm{C}$ for about $15 \mathrm{~min}$ to remove last traces of pentane before weighing: When the nonvolatile material in these fractions had 
reached a constant value (in the order of $0.025 \mathrm{~g}$, when $5 \mathrm{~g}$ of asphalt was being processed), all previous fractions up to this point were combined. This fraction of the asphalt was designated "water-white oils."

After the $n$-pentane elution, methylene chloride was passed through the column until the eluate was practically colorless and the glass-wool plug at the bottom of the column was free from stain. The $n$-pentane holdup in the column was collected with this fraction. The eluents were evaporated from this solution on a steam bath. Water and traces of the eluents, if present, were removed by heating at $105^{\circ} \mathrm{C}$ for about $10 \mathrm{~min}$ before weighing. This fraction of the asphalt was designated as "dark oils."

Following the elution with methylene chloride, methyl ethyl ketone was passed through the column until the eluate was colorless. The methylene chloride holdup was collected with this fraction. This fraction, designated as asphaltic resins, was treated in the same manner as the previous one before weighing.

During the latter part of the investigation, R. W. Faid and D. C. McLean ${ }^{5}$ suggested the use of a mixture of 10 percent of water and 90 percent of acetone ${ }^{6}$ followed by chloroform ${ }^{7}$ for the removal of the major portion of the materials not removed by the $n$-pentane, methylene chloride, and methyl ethyl ketone. When this step was taken, the acetone-water mixture and chloroform eluates were collected together and freed from solvents in the same manner as that used for methylene chloride before weighing. This small fraction of the asphalt was designated "acetone-chloroform desorbed."

\section{Description and Distribution of Fractionated Components}

The four principal components obtained in the fractionation had distinctly different physical characteristics. The asphaltenes were black, brittle, hard solids, which intumesce rather than melt when heated. The water-white oils were colorless when freshly prepared and had about the same viscosity as a heavy lubricating oil at room temperature. The dark oils were reddish-orange in color and had a very high viscosity at room temperature. The asphaltic resins were glossy, brownish-black solids at room temperature. The small fractions of acetone-chloroform desorbed material obtained in the later experiments were black solids slightly harder than the asphaltic resins.

The results shown in table 1 are typical of those obtained in repeated determinations of the percentage of each fractionated component in specimens of the same asphalt. In this case a blown petroleum

\footnotetext{
5 Chemists, Mexican Petroleum Corporation, Baltimore, Md.

6 Technical grade. It was found later that the acetone-water mixture used in deactirating the fuller's earth could be eliminated if water-saturated methyl ethyl ketone was used instead of the technical grade.

7 United States Pharmacopoeia grade.
}

TABLE 1. Repeatability of determinations a with specimens from the same asphalt

\begin{tabular}{|c|c|c|c|c|}
\hline Determination Number & 1 & 2 & 3 & A verage \\
\hline Asphaltenes & 39.8 & 39.2 & 38.4 & 39.1 \\
\hline Water-white oils. & 24.5 & 24.7 & 24.0 & 24.4 \\
\hline Dark oils _....... & 22.9 & 23.8 & 23.3 & 23.3 \\
\hline Asphaltic resins & 9.6 & 10.1 & 10.2 & 10.0 \\
\hline Total recovered & 96.8 & 97.8 & 95.9 & 96.8 \\
\hline
\end{tabular}

a Fifteen parts of fuller's earth used for each part of the $n$-pentane soluble material.

TABLE 2. Distribution of the fractionated components of six shingle coating asphalts from different geographical sources ${ }^{\text {a }}$

\begin{tabular}{|c|c|c|c|c|c|c|}
\hline Asphalt _. & A & $\mathrm{B}$ & $\mathrm{C}$ & $\mathrm{D}$ & $\mathrm{E}$ & $\mathrm{F}$ \\
\hline $\begin{array}{c}\text { Softening point }(\mathrm{R} \& \mathrm{~B} \\
\text { method }\end{array}$ & & 104 & 108 & 111 & 96 & 102 \\
\hline Asphaltenes & 43. 6 & 42.2 & 39.1 & 40.5 & 37.5 & 37.4 \\
\hline Water-white oils & 20.2 & 20.0 & 28.3 & 27.3 & 26.0 & 21.0 \\
\hline Dark oils... & 25.3 & 25.2 & 22.8 & 20.0 & 21.8 & 24.6 \\
\hline Asphaltic resins & 6.9 & 9.1 & 8.0 & 9.5 & 11.0 & 12.8 \\
\hline Acetoneb-chloroform & & & & & & \\
\hline $\begin{array}{l}\text { desorbed } \\
\text { Total recovered }\end{array}$ & 1. 97 & $\begin{array}{r}1.3 \\
97.8\end{array}$ & $\begin{array}{r}0.9 \\
99.1\end{array}$ & $\begin{array}{r}2.0 \\
99.3\end{array}$ & $\begin{array}{r}1.9 \\
98.2\end{array}$ & $\begin{array}{r}2.5 \\
98.3\end{array}$ \\
\hline
\end{tabular}

a Fifteen parts of fuller's earth was used for each part of the $n$-pentane soluble material.

b Acetone plus 10 percent of water.

asphalt with a softening point ${ }^{8}$ of approximately $95^{\circ} \mathrm{C}$ was fractionated, using 15 parts of fuller's earth to each part of $n$-pentane soluble material. After the methyl ethyl ketone desorption in these analyses, the fuller's earth at the top of the column was darkened slightly (evidence of nondesorbed material). Very little, if any of this strongly adsorbed material was removed by successive washing with ethyl ether, ethyl and methyl alcohols, acetone, benzol, chloroform, and carbon tetrachloride. Water alone caused swelling of the fuller's earth, which obstructed the flow by gravity. When external pressure was applied above the water, the fuller's earth swelled to the extent of breaking the glass tubing.

Table 2 shows the distribution of the fractionated components obtained from six blown petroleum asphalts produced from fluxes of different geographical origin. The percentages of material recovered by the acetone-water mixture and chloroform wash are also reported in this table.

Although this method of fractionating asphalts was developed primarily for the study of changes occurring in the various components during the weathering of blown asphalts, it also facilitates the examination of vacuum-reduced asphalts and fluxes used in the preparation of the blown asphalts.

Table 3 shows the distribution of the fractionated components obtained from three blown petroleum asphalts and from the fluxes from which they were prepared.

Table 4 shows how the distribution of the $n$ pentane soluble components was effected by varying the ratio of the amount of fuller's earth to that of

8 Tentative method of test for softening point, ball and shouldered ring apparatus, ASTM Designation E2S-42T. 
TABLE 3. Distribution of fractionated components in three blown shingle coating asphalts and in the fluxes from which they were produced a

\begin{tabular}{|c|c|c|c|c|c|c|}
\hline \multirow{2}{*}{$\begin{array}{l}\text { Asphalt } \ldots \ldots \\
\text { Type. }\end{array}$} & \multicolumn{2}{|c|}{ G } & \multicolumn{2}{|c|}{$\mathrm{H}$} & \multicolumn{2}{|c|}{ I } \\
\hline & Flux & $\begin{array}{c}\text { Coat- } \\
\text { ing }\end{array}$ & Flux & $\begin{array}{c}\text { Coat- } \\
\text { ing }\end{array}$ & Flux & $\begin{array}{c}\text { Coat- } \\
\text { ing }\end{array}$ \\
\hline Asphaltenes & 19.4 & 37.8 & 13.1 & 39.1 & 13.2 & 41.8 \\
\hline Water-white oils & 20.8 & 19.5 & 28.0 & 24.4 & 32.4 & 27.4 \\
\hline Dark oils ... & 42.0 & 28.0 & 38.4 & 23.3 & 29.6 & 18. 2 \\
\hline Asphaltic resins & 14.1 & 11.9 & 14.9 & 9.9 & 16.8 & 10.3 \\
\hline $\begin{array}{l}\text { Acetone b-chloroform de- } \\
\text { sorbed }\end{array}$ & 2.0 & 1.3 & 2.0 & & 3.8 & \\
\hline Total recovered & 98.3 & 98.5 & 96.4 & 96.7 & 95.8 & 97.7 \\
\hline
\end{tabular}

a Fifteen parts of fuller's earth was used for each part of the $n$-pentane soluble material.

$\mathrm{b}$ Acetone plus 10 percent of water.

TABLE 4. Influence of the ratio of the amount of fuller's earth to that of the n-pentane soluble material on the distribution of the water-white oils, dark oils, and asphaltic resins

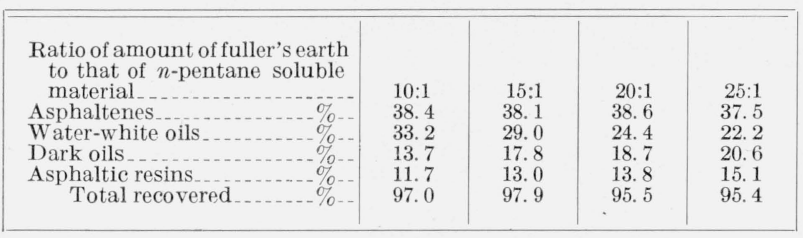

the $n$-pentane soluble material of a blown petroleum asphalt having a softening point of approximately $85^{\circ} \mathrm{C}$ ( $\mathrm{R} \& \mathrm{~B}$ method). In changing this ratio from $10: 1$ to $25: 1$, the percentage of water-white oils decreased by a factor of 3 to 2 , whereas the percentages of the dark oils and asphaltic resins increased by about the same factor.

\section{Conclusion}

The procedure described provides a rapid and reproducible method of fractionating asphalts into four distinct groups of components. The fractionation of asphalts in this manner facilitates chemical studies of the degradation of asphalts under service conditions. The method is well suited for samples as small as those (about $5 \mathrm{~g}$ ) used in conventional weathering and accelerated durability tests.

\section{References}

[1] J. Marcusson, Die Naturlieken und Kunstlieken Asphalts, 2d ed. (Leipzig, Verlag Von Wilhelm Engleman, 1931).

[2] O. G. Strieter, J. Research NBS 26, 415 (1941) RP1387.

[3] Rethel L. Hubbard and K. E. Stanfield, Anal. Chem. 20, 460 (1948).

[4] Gordon O'Donnell, Anal. Chem. 23, 894 (1951).

[5] Herbert Abraham, Asphalts and allied substances, 5th ed., vol. 2, P. 1224 (D. Van Nostrand Co., Inc., New York, N. Y., 1945)

[6] F. R. Grant and A. J. Hoiberg, Proc. Assoc. Asphalt Paving Technol. 12, 87 (1940).

[7] R. N. Traxler and H. E. Schweyer, Oil Gas J. (Aug. 31, 1953).

[8] Fritz S. Rostler and Heinz W. Sternberg, Ind. Eng. Chem. 41, 598 (1949).

[9] Sidney H. Greenfield, Bull. No. 193, ASTM (Oct. 1953).

Washington, November 15, 1954. 